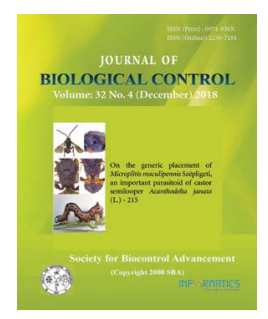

\title{
Biology and rearing protocol for Dortus primarius Distant, a predatory mirid (Hemiptera: Miridae)
}

\author{
RICHA VARSHNEY ${ }^{*}$, H. M. YESHWANTH ${ }^{2}$ and CHANDISH R. BALLAL ${ }^{1}$ \\ ${ }^{1}$ ICAR-National Bureau of Agricultural Insect Resources, P.B. No. 2491, HA Farm Post, Bellary Road, Hebbal, \\ Bangalore - 560024, Karnataka, India \\ ${ }^{2}$ Department of Entomology, GKVK, University of Agricultural Sciences, Bangalore - 560065, Karnataka, India \\ ${ }^{*}$ Corresponding author E-mail: richavarshney84@gmail.com
}

\begin{abstract}
Dortus primarius Distant (Miridae: Deraeocorinae) was observed to feed on thrips and other soft bodied insects in the field. Biology, morphology and feeding potential of this species were studied for the first time in the laboratory (at $26 \pm 2{ }^{\circ} \mathrm{C}$ and $65 \pm 2 \% \mathrm{RH}$ ) on $\mathrm{UV}$ irradiated Corcyra cephalonica (Stainton) eggs. A total of five instars were observed, with nymphal duration of 17.2 days. Mean fecundity was 127.6 eggs per female. Female longevity was higher than male. One nymph could consume a total of 363 C. cephalonica eggs in its life span. Adult male and female fed on a total of 713 and 1014.75 eggs, respectively. Cost of producing 100 D. primarius nymphs and adult nymphs neonate/first instar was INR 10.34/- and INR 200/-, respectively. In this paper all immature stages, eggs and adults are described with live images. Results showed that this species could be reared on UV irradiated C. cephalonica eggs and bean pieces successfully. Further studies are needed to evaluate this species against insect pests in field.
\end{abstract}

KEYWORDS: Biology, Dortus primarius, feeding potential, mirid bug, rearing protocol

(Article chronicle: Received: 07-7-2018; Revised: 22-11-2018; Accepted: 05-12-2018)

\section{INTRODUCTION}

Deraeocorinae is a widely distributed subfamily of Miridae. It comprises of six tribes (Schuh, 2002-13). The members of this subfamily are considered to be general predators. Some are specialized predators having specific pest preferences viz. termatophylines (Termatophylidea Reuter and Poppius, Termatophylum Reuter and Fingulus Distant) prefering thrips, Stethoconus Flor prefering lace bugs. Therefore, Deraeocorines are considered to be economically important in agriculture and forest ecosystems (Wheeler, 2001).

Dortus primarius Distant (Hemiptera: Miridae) belongs to subfamily Deraeocorinae with two species known so far in the genus viz., D. primarius Distant and D. chinai Miyamoto. Members of tribe Deraeocorini are reported to feed on eggs (Lepidoptera, Heteroptera, Coleoptera, etc.), larvae and pupae (Lepidoptera and Coleoptera), thrips and mites (Wheeler, 2001). However, some plant feeding occurs in this subfamily of Heteroptera but the extent of feeding is not clear (Schaefer and Panizzi, 2000). Perhaps, plant feeding might enhance their survival in adverse conditions. Dortus primarius was recorded in cauliflower, okra, brinjal in association with thrips and other soft bodied insects. Not much biological information is available for this mirid species. However, there are reports on biological parameters of other members of Deraeocorini. Deraeocoris spp. have also been recognized as efficient predators of whiteflies (Susman 1988, Kapadia and Puri, 1991; Jones and Snodgrass, 1998). Deraeocoris brevis (Uhler) was reported as a predator of pear psylla, spider mites, aphids and leafhoppers (McMullen and Jong, 1967; Westigard et al., 1968, Kim and Riedl, 2005) and Deraeocoris nebulosus (Uhler) of whiteflies (Jones and Snodgrass, 1998).

In this study, attempts were made to rear $D$. primarius in the laboratory on factitious host and biology, feeding potential and rearing requirements was studied in detail. Detailed descriptions of all the stages with images are presented and discussed in this paper. The aim of the study was thus to generate basic information on this mirid which can further be utilized to study its potential against soft bodied insects in field situations. 


\section{MATERIAL AND METHODS}

Dortus primarius was collected from okra, brinjal, cauliflower crops where it was associated with thrips and other soft bodied insects. The specimens were studied under stereo zoom binocular microscope. Photographs of different nymphal instars and adult were taken using a Leica M205C. Eggs of Corcyra cephalonica (Stainton) (Lepidoptera: Pyralidae) (National Accession number: NBAII-MP-PYR-01) were used for rearing of $D$. primarius.

\section{Rearing protocol and morphometry}

Dortus primarius was reared in the laboratory on french bean pods and UV-irradiated Corcyra cephalonica eggs. Plastic containers (Pearlpet $^{\circledR}, 500 \mathrm{ml}$ capacity) were used for rearing. The floor of the containers was provided with tissue paper. In each container, 5-6 pieces of bean pods were placed as oviposition substrate along with cotton lint (to avoid cannibalism), on which $C$. cephalonica eggs were sprinkled. A cotton swab soaked in water was stuck to the inner wall of the container for moisture requirements. One container could hold 20-25 adults.

Adult females laid their eggs on the side of bean pods either singly or in small groups (usually 3-4), inserted into the tissue with only the operculum visible. After 24 hours, the bean pods with eggs were removed and placed in small, round, ventilated plastic containers (diameter $6.5 \mathrm{~cm}$ and height 2.5 $\mathrm{cm})$. When the nymphs started hatching, they were shifted to Pearlpet ${ }^{\circledR}$ jars $(200 \mathrm{ml})$ provided with C. cephalonica eggs (ad libitum) on bean pods. C. cephalonica eggs were provided for feeding on every alternate day till the nymphs developed into adults. The fresh adults were shifted into the Pearlpet ${ }^{\mathbb{B}}$ jars (500 ml capacity) for mating and egg laying. These containers were placed in an incubator set at $25^{\circ} \mathrm{C}, 60-70 \%$ RH, and a photoperiod of 12:12 (L: D) h. Nymphal and adult stages were measured by using ocular and stage micrometers. The measurements indicated in the text are expressed in millimeters.

\section{Biological parameters}

Dortus primarius was reared for four generations on C. cephalonica eggs by following the above protocol in order to acclimatize to the laboratory host/conditions before initiating the experiments. To study biology, one pair of adults was released into each pearl pet plastic container $(200 \mathrm{ml})$ covered with black cloth. Ten such sets were maintained. Each container was provided with UV-irradiated C. cephalonica eggs as feeding, bean pieces (2-3) half inch long for egg laying and moisture provided in the form of water-soaked cotton swab. After every $24 \mathrm{~h}$, bean pods were collected and observed under microscope to record number of eggs laid.
Eggs were collected, counted and beans with eggs were placed in small, round, ventilated plastic boxes (diameter 6.5 $\mathrm{cm}$ and height $2.5 \mathrm{~cm}$ ) for hatching.

The number of nymphs, which hatched from total eggs collected from each container, was counted for calculating per cent hatching. Ten freshly hatched nymphs per set were kept individually in plastic boxes provided with UV-irradiated C. cephalonica eggs. Observations were recorded on total number of instars, duration of each instar and total nymphal period. When adults were formed, they were collected and observed under microscope to differentiate the sex. Per cent adults formed was calculated based on the number of healthy adults developed from the total number of nymphs which hatched in each set. Longevity of male and female adult D. primarius was recorded.

\section{Feeding potential}

To study the feeding potential in the laboratory, nymphs and adults of the fourth generation were used. Freshly hatched nymphs were kept individually in plastic jewel boxes $(6.5 \times 6.5 \times 2.7 \mathrm{~cm})$. Twenty UV-irradiated C. cephalonica eggs were placed on bean pod for $1^{\text {st }}$ and $2^{\text {nd }}$ instar nymph, for $3^{\text {rd }}$ instar nymph 30 eggs and for $4^{\text {th }}$ and $5^{\text {th }}$ instar nymph, 50 UV-irradiated C. cephalonica eggs were placed on bean pod inside each box. For adults $60 \mathrm{UV}$-irradiated C. cephalonica eggs were placed on bean pod. After every $24 \mathrm{~h}$, the eggs were examined under microscope for feeding damage and the number of eggs fed was recorded.

\section{Statistical analysis}

Each experiment was replicated five times and the arithmetic mean and standard error of mean was estimated for all the parameters/observations. Range values were also estimated by pooling up the replication data for each parameter.

\section{RESULTS AND DISCUSSION}

\section{Morphology and biology: (Table 1 and 2)}

It was observed that Dortus primarius laid 118-145 eggs either singly or in groups of 3 and 4 eggs embedded on the lateral side of bean pod, with the red colour operculum visible. One white thread like structure is present on one side of operculum (Fig. 1). After 7-8 days nymphs start hatching. The newly hatched nymphs when fed on UV-irradiated eggs of Corcyra cephalonica, undergo five nymphal instars and became adults in about 14-17 days.

First instar: Total length-1.36, width-0.56, antennal length-1.02, labium- 0.68 , pronotum width- 0.36 , head width with compound eye: $0.43,1^{\text {st }}$ antennal segment length: 0.15 , 
Table 1. Morphometry of Dortus primarius

\begin{tabular}{|c|c|c|c|c|c|c|}
\hline \multicolumn{2}{|c|}{ Developmental stage } & \multirow{2}{*}{$\begin{array}{l}\begin{array}{l}\text { Width } \\
(\mathrm{mm})\end{array} \\
\text { Mean } \pm \mathrm{SE}\end{array}$} & \multirow{2}{*}{$\begin{array}{l}\begin{array}{l}\text { Length } \\
(\mathrm{mm})\end{array} \\
\text { Mean } \pm \mathrm{SE} \\
\end{array}$} & \multirow{2}{*}{$\begin{array}{l}\text { Labium }(\mathrm{mm}) \\
\text { Mean } \pm \mathrm{SE} \\
\end{array}$} & \multirow{2}{*}{$\begin{array}{l}\begin{array}{l}\text { Antenna } \\
(\mathrm{mm})\end{array} \\
\text { Mean } \pm \mathrm{SE}\end{array}$} & \multirow{2}{*}{$\begin{array}{l}\begin{array}{l}\text { Pronotum } \\
(\mathrm{mm})\end{array} \\
\text { Mean } \pm \mathrm{SE}\end{array}$} \\
\hline & & & & & & \\
\hline \multirow[t]{5}{*}{ Nymph } & $1^{\text {st }}$ instar & $0.56 \pm .004$ & $1.36 \pm .013$ & $0.68 \pm .003$ & $1.02 \pm .01$ & $0.36 \pm .008$ \\
\hline & $2^{\text {nd }}$ instar & $0.95 \pm .005$ & $2.12 \pm .012$ & $0.89 \pm .004$ & $1.61 \pm .013$ & $0.59 \pm .004$ \\
\hline & $3^{\text {rd }}$ instar & $1.35 \pm .012$ & $2.79 \pm .012$ & $1.25 \pm .006$ & $2.15 \pm .004$ & $0.83 \pm .002$ \\
\hline & $4^{\text {th }}$ instar & $1.50 \pm .013$ & $3.44 \pm .011$ & $1.42 \pm .009$ & $2.61 \pm .036$ & $0.92 \pm .002$ \\
\hline & $5^{\text {th }}$ instar & $1.74 \pm .011$ & $3.80 \pm .016$ & $1.45 \pm .013$ & $2.74 \pm .008$ & $1.13 \pm .002$ \\
\hline \multirow[t]{2}{*}{ Adult } & Male & $1.78 \pm .004$ & $3.95 \pm .004$ & $1.70 \pm .008$ & $2.80 \pm .007$ & $1.51 \pm .006$ \\
\hline & Female & $1.89 \pm .007$ & $4.49 \pm .017$ & $1.67 \pm .004$ & $2.79 \pm .006$ & $1.53 \pm .002$ \\
\hline
\end{tabular}

Table 2. Biology of Dortus primarius reared on Corcyra cephalonica eggs

\begin{tabular}{lll}
\hline Stage & Mean \pm SE & Range \\
\hline Incubation period (days) & $8 \pm 0.31$ & $7-9$ \\
Pre-oviposition period (days) & $4 \pm 0.32$ & $3-5$ \\
Duration of nymphal instars & & \\
(days) & & \\
I & $3.6 \pm 0.25$ & $3-4$ \\
II & $2.6 \pm 0.25$ & $2-3$ \\
III & $2.8 \pm 0.20$ & $2-3$ \\
IV & $2.6 \pm 0.25$ & $2-3$ \\
V & $3.6 \pm 0.25$ & $3-4$ \\
Total nymphal period (days) & $17.2 \pm 0.32$ & $16-18$ \\
Total developmental period & - & \\
(days) (eggs to adult) & & \\
Male & $21.8 \pm 0.37$ & $21-23$ \\
Female & $23.4 \pm 0.51$ & $22-25$ \\
Longevity of male (days) & $14.6 \pm 0.51$ & $13-16$ \\
Longevity of female (days) & $20.2 \pm 0.37$ & $19-21$ \\
Eggs/female & $127.6 \pm 4.95$ & $118-145$ \\
Nymphs/female & $116.0 \pm 4.48$ & $108-132$ \\
Per cent eggs hatched & $91.0 \pm 0.44$ & $90-92$ \\
Per cent adults developed & $73.2 \pm 0.70$ & $71.2-75.2$ \\
\hline
\end{tabular}

$2^{\text {nd }}$ antennal segment length: $0.31,3^{\text {rd }}$ antennal segment length: $0.25,4^{\text {th }}$ antennal segment length: 0.32 , hind leg: femur: 0.41 , tibia:0.54 and tarsus: 0.20 (Table 1). Young nymph is greenish yellow in colour. Head and thorax are yellow in color; abdomen brownish yellow; Antenna is 4 segmented and pale in colour, Basal segment is reddish brown. Lower part of $2^{\text {nd }}$ and $3^{\text {rd }}$ segment of antenna is yellow in color. Apex segment of antenna is brown in colour; a yellow round mark is visible in middle segment of abdomen. Setae are dispersed all over the body. A reddish brown thick line structure is present at distal end of abdomen (anal tube). Legs are light yellow with red hue on femora and tibia. Rostrum extending to hind coxae. Tip of rostrum is brown. Duration is 3-4 days (Fig. 1).

Second instar: Total length-2.12, width- 0.95 , antennal length-1.61, labium- 0.89 , pronotum width- 0.59 , head width with compound eye: $0.56,1^{\text {st }}$ antennal segment length: 0.28 , $2^{\text {nd }}$ antennal segment length: $0.52,3^{\text {rd }}$ antennal segment length: $0.39,4^{\text {th }}$ antennal segment length: 0.41 , hind leg: femur: 0.67 , tibia: 0.92 and tarsus: 0.33 . White ' $v$ ' shaped structure is present at proximal end of head. Anal tube appears as a brown tail like structure for each instar. Setae are present all over the body. Duration is 2-3 days (Fig. 1).

Third instar: Total length-2.79, width-1.35, antennal length-2.15, labium-1.25, pronotum width- 0.83 , head width with compound eye: $0.65,1^{\text {st }}$ antennal segment length: 0.34 , $2^{\text {nd }}$ antennal segment length: $0.75,3^{\text {rd }}$ antennal segment length: $0.52,4^{\text {th }}$ antennal segment length: 0.46 , hind leg: femur: 0.81 , tibia:1.06 and tarsus: 0.32 . Wing pad starts developing and occupying upper $1 / 3^{\text {rd }}$ area of abdomen. Tip of rostrum is deep brown in colour. Eyes are deep brown. Body is covered with pilose setae. The average duration of third instar nymph is 2-3 days

Fourth instar: Total length-3.44, width-1.50, antennal length-2.61, labium-1.42, pronotum width-0.92, head width with compound eye: $0.77,1^{\text {st }}$ antennal segment length: 0.37 , $2^{\text {nd }}$ antennal segment length: $0.98,3^{\text {rd }}$ antennal segment length: $0.64,4^{\text {th }}$ antennal segment length: 0.54 , hind leg: femur: 1.22, tibia: 1.59 and tarsus: 0.45 . Antenna: basal segment is deep brown; apical and basal part of second segment is brown while middle part is yellow in colour; third and fourth segments are brown with basal portion yellow in colour. Wing 
pads grow and occupy the middle part of abdomen. Body is densely covered with bristle like setae. Average duration is 2-3 days (Fig. 1).

Fifth instar: Total length-3.80, width-1.73, antennal length-2.74, labium-1.45, pronotum width-1.12.The fifth instar moults to become an adult in 3-4 days. Body is covered with stout bristle like setae. A reddish brown thick line structure is present at distal end of abdomen (anal tube) Mean nymphal period for this mirid was 15.2 days. Male emerges 1-2 days prior to female.

Adult female: Total length-4.49, width-1.89, antennal length-2.79, labium-1.61, pronotum width-1.53, vertex width: 0.46 , head width with compound eye: $0.92,1^{\text {st }}$ antennal segment length: $0.42,2^{\text {nd }}$ antennal segment length: $1.28,3^{\text {rd }}$ antennal segment length: $0.62,4^{\text {th }}$ antennal segment length: 0.47 , hind leg: femur: 1.46 , tibia: 1.93 and tarsus: 0.52 , outer cuneal margin length (straight): 0.80 , outer embolial margin length (straight): 2.24 (Table 1, Fig. 1).

Adult male: Total length-3.96, width-1.78, antennal length-2.80, labium-1.70, pronotum width-1.49, vertex width:, head width with compound eye:, $1^{\text {st }}$ antennal segment length: $0.41,2^{\text {nd }}$ antennal segment length: $1.35,3^{\text {rd }}$ antennal segment length: $0.72,4^{\text {th }}$ antennal segment length: 0.59 , hind leg: femur: 1.45 , tibia: 1.92 and tarsus:0.55, outer cuneal margin length (straight): 0.72 , outer embolial margin length (straight): 2.04 (Fig. 1).

Colouration: Pale brown shining bugs, eyes black completely; Antenna: first segment of antenna, II segment: basal $1 / 4$ and apical $1 / 2$ dark brown or black; segment III: basal $1 / 4$ pale, apical $4 / 4$ and segment IV dark brown; Legs with apical $1 / 4$ of femur slightly darker; hemelytra with claval commissure, region above cuneus on corium and apex of cuneus and the margins of cells dark brown. Surface structure: Head, Scutellum and legs are shining smooth; pronotum deeply punctuate; dorsum covered with sub erect elongate golden yellow setae.

Head strongly produced in front wider than long; eyes occupying the entire height of the head; I segment of antenna longer than intraocular width; segment II longest longer than segment III and IV combined. Pronotum with prominent shining calli; lateral margins weekly concave, posterior margin concave; Scutellum medially convex; hemelytra with prominent emoblium; cuneus longer than width; membrane with two closed cells with small triangular inner and our elongate larger cell; legs elongate with cylindrical femur; tibia elongate, tarsi three segmented with claws dentate basally.
Male genitalia: genital capsule broader than long, with apex rounded border at base; Left paramere long with prominent basal lobe, medially elongate curved with apex beak- like; right paramere slender and elongate curved in middle with apex pointed; aedeagus with a prominent phallotheca; endosome membranous with large group of spicules on the basal region and small groups of spicules near apex and the apex pointed and sclerotized.

Males and females can be differentiated based on the appearance of abdomen observed from the ventral side. In males the tip of the abdomen is rounded and parameres are seen laterally near apex. In females, the ovipositor is clearly visible when observed ventrally (Fig. 2). Males are slender and shorter in size than females.

\section{Biology}

Mean pre-oviposition period and incubation period of $D$. primarius was 4 and 8 days, respectively. The mean nymphal durations for first, second, third, fourth and fifth instar was 3.6, 2.6, 2.8, 2.6 and 3.6 days, respectively and total nymphal period was 17.2 days (Table 2). Male emerges before female in this species. Mean developmental period for male (21.8 days) was shorter than female (23.4 days). A female laid an average of 127.6 eggs in its life span. Longevity of male and female adult was 14.6 and 20.2 days, respectively. Egg laying started 4 days after emergence of adult and continued till the death of female (Table 2). Per cent hatching was 91. Jones and Snodgrass (1998) reported nymphal period of 13.3 days and fecundity of 242.3 eggs per female for Deraeocoris nebulosus (Uhler) which belongs to same tribe when fed on whitefly Bemisia argentifolii as prey. For Deraeocoris sp. mean nymphal period and mean developmental period were 15.4 and 25.5 days, respectively (Kapadia and Puri, 1991) when fed on Bemisia tabaci (Gennadius). This finding is comparable to the present study.

\section{Feeding potential}

Feeding potential of D. primarius on C. cephalonica eggs was studied to quantify number of eggs required for successful rearing in laboratory. Mirids have sucking type of mouth parts. It pierces host eggs and suck out the content. First, second, third, fourth and fifth instar could consume $20.4,30.8,53.8,88.2$ and 169.8 eggs, respectively during their developmental period. The total consumption of eggs during the nymphal period was 363 . First and second instars were also observed to feed on plants. Among all the nymphal instars, minimum feeding (4.6 and 4.8 eggs per day) was observed during first two days after hatching when it initiated feeding on host eggs. Maximum feeding was observed in $5^{\text {th }}$ instar on the $14^{\text {th }}$ and $15^{\text {th }}$ day when the nymph was about 
to turn into adult. The feeding potential of each instar was higher than the previous instar (Table 3, Fig. 3). Per day feeding potential of female (50.75) was slightly higher than male (47.5). Total feeding by one female during its entire life span was 1014.75 eggs and for male it was 713 eggs (Table 3). Higher feeding rate in female may be due to its higher longevity and nutrients requirements to produce eggs. Cannibalism was also observed in advanced stage of this species when confined. Kapadia and Puri (1991) also reported higher predation on $\mathrm{B}$. tabaci by female Deraeocoris sp. compared to male. To the best of our knowledge no work has been carried out on biology and feeding potential of D. primarius on C. cephalonica eggs.

The earlier studies have evaluated the predation capacity of few mirid predators on the target pests, while through this study; authors have studied the predation capacity on the laboratory host eggs, which is essential to arrive at a feasible mass production protocol.

Based on the feeding potential, cost of production of nymphs and adults of $D$. primarius was calculated considering the cost of host eggs alone as follows:

1 cc of $C$. cephalonica eggs costing Rs.60/= contains 16,000 eggs

1 cc of C. cephalonica eggs can be used to feed $10 \mathrm{D}$. primarius adults@1727eggs per pair (adult male and female)

Considering 1:1 sex ratio, out of 10 adults, 5 are females

5 females can produce 580 nymphs (@116 nymph/ female)

Table 3. Feeding potential of nymph and adult of Dortus primarius on Corcyra cephalonica eggs

\begin{tabular}{lll}
\hline Stage & $\begin{array}{l}\text { Average no. of } \\
\text { eggsa consumed/ } \\
\text { day/individual }\end{array}$ & $\begin{array}{l}\text { Total no. of } \\
\text { eggsa consumed by } \\
\text { nymph/adult }\end{array}$ \\
\hline $1^{\text {st }}$ instar nymph & $5.1 \pm 0.23$ & $20.4 \pm 0.51$ \\
$2^{\text {nd }}$ instar nymph & $10.3 \pm 0.18$ & $30.8 \pm 0.91$ \\
$3^{\text {rd }}$ instar nymph & $17.9 \pm 0.70$ & $53.8 \pm 2.39$ \\
$4^{\text {th }}$ instar nymph & $29.4 \pm 0.76$ & $88.2 \pm 2.73$ \\
$5^{\text {th }}$ instar nymph & $42.45 \pm 0.53$ & $169.8 \pm 2.71$ \\
$\begin{array}{l}\text { Total feeding by } \\
\text { nymph }\end{array}$ & - & $363 \pm 3.56$ \\
Adult male & $47.5 \pm 0.65$ & $713 \pm 26.35$ \\
Adult female & $50.75 \pm 1.44$ & $1014.75 \pm 32.75$ \\
\hline
\end{tabular}

aall values are expressed as means \pm se
Cost of production of 580 nymphs is Rs.60/-,

Cost of production of 100 D. primarius nymphs is Rs. $10.34 /$

From 580 nymphs (with adequate feeding), 424 adults can be obtained (73.18\% adult emergence)

2, 10, 540 or 13.15 cc C. cephalonica eggs (costing Rs. 789/=) are required to feed 580 nymphs @ 363 eggs per nymph.

Cost of production of 424 adults being Rs. 849/= (i.e., Rs. 60+ Rs. 789)

\section{Cost of production of 100 D. primarius adults is Rs. 200/-}

These results demonstrate that $D$. primarius is highly amenable to rearing and can develop and survive in the laboratory when reared on UV irradiated $C$. cephalonica eggs with french bean pods as oviposition substrate. Basic information like biology and feeding potential of predators are essential to understand their rearing requirement, so that they are available for field releases. The present study has reported the biology, rearing protocol and feeding potential with illustrations on morphology of eggs and immature stages of $D$. primarius for the first time. Basic information generated through the present study can be a base for further field evaluation of this species. Further studies on prey preference and interaction with other natural enemies are warranted.

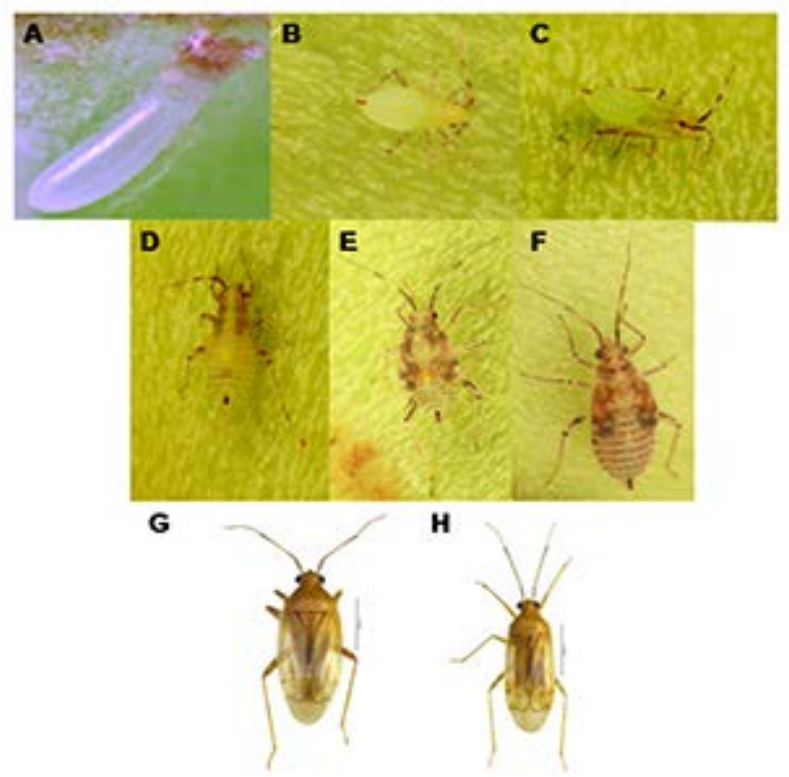

Fig. 1. Different life stages of Dortus primarius: A: Egg; B-F: Nymphal instars; G: Female; H: Male 

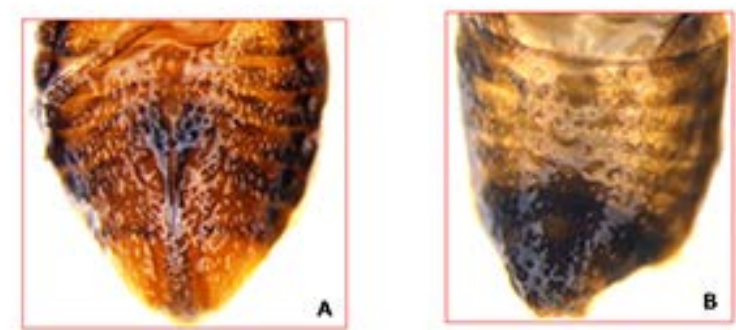

Fig. 2. A: Female abdomen, B: Male abdomen

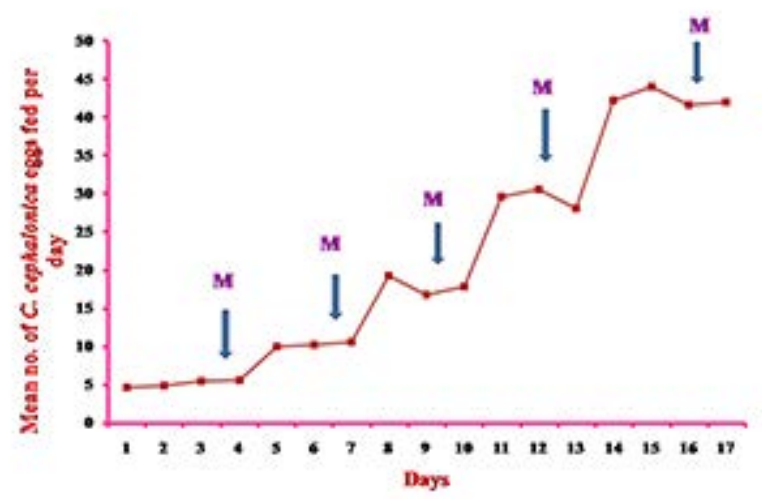

Fig. 3. Day-wise feeding potential of nymph of Dortus primarius on Corcyra cephalonica eggs

\section{ACKNOWLEDGEMENTS}

The authors are grateful to the Indian Council of Agricultural Research, India, for the facilities provided for conducting the study. Authors are thankful to Dr. Y. Lalitha for providing Corcyra cephalonica eggs.

\section{CONFLICT OF INTEREST}

The authors declare that they have no conflict of interest.

\section{REFERENCES}

Distant WL. 1910. Descriptions of Oriental Capsidae. Ann Mag Nat Hist 8(5): 10-22. https://doi. org/10.1080/00222931008692721

Jones WA, Snodgrass GL. 1998. Development and fecundity of Deraeocoris nebulosus (Heteroptera: Miridae) on Bemisia argentifolii (Homoptera: Aleyrodidae). Fla. Entomol. 81(3): 345-350. https://doi.org/10.2307/3495924

Kapadia MN, Puri SN. 1991. Biology and comparative predation efficacy of three heteropteran species recorded as predators of Bemisia tabaci in Maharashtra. Entomophaga. 36: 555-559. https://doi.org/10.1007/ BF02374438

Kim DS, Riedl H. 2005. Effect of temperature on development and fecundity of the predaceous plant bug Deraeocoris brevis reared on Ephestia kuehniella eggs. Biocontrol 50: 881-897. https://doi.org/10.1007/s10526-005-5380-x

Lin CS, Yang CT. 2005. External male genitalia of the Miridae (Hemiptera: Heteroptera). Nat Mus Natur Sci Spec Publ. 9: 1-174.

McMullen RD, Jong C. 1967. New records and discussion of predators of the pear psylla, Psylla pyricola Foerster, in British Columbia. J Entomol Soc British Columbia. 64: 35-40.

SchaeferCW,PanizziAR.(eds.).2000. Heteroptera of Economic Importance. Boca Raton: CRC Press. 828 pp. ISBN 0-8493-0695-7. https://doi.org/10.1201/9781420041859

Schuh RT. 2002-2013. Online Systematic Catalog of Plant Bugs (Insecta: Heteroptera: Miridae). The American Museum of Natural History. Available at: http://research. amnh.org/pbi/catalog/

Susman I. 1988. The cotton insects of Israel and aspects of the biology of Deraeocoris pallens Reuter (Heteroptera, Miridae), predators of the tobacco whitefly Bemisia tabaci in Israel. M.S. Thesis, Tel Aviv University, 154 pp. (In Hebrew with English summary).

Westigard PH, Gentner LG, Berry DW. 1968. Present status of biological control of the pear psylla in southern Oregon. J Econ Entomol. 61: 740-743. https://doi.org/10.1093/jee/61.3.740

Wheeler AG. 2001. Biology of the Plant Bugs (Hemiptera: Miridae): Pests, Predators, Opportunists. New York: Cornell University Press. 